\title{
The effectiveness of brain metastases radiotherapy in patients with melanoma
}

\author{
Bogumiła Szyszka-Charewicz
}

\begin{abstract}
Introduction. Melanoma gives rise to 7-13\% brain metastases (MBM - melanoma brain metastases) and is ranked third leading cause of brain metastases. The prognosis of patients with MBM is poor, with a median survival time of 3-6 months. Assessment of the value and limitations of three prognostic scores used in patients with melanoma brain metastases (MBM) was presented in this paper.

Material and methods. In 110 patients with MBM, we executed an analysis of prognostic factors. All patients were treated with radiotherapy: whole brain radiotherapy performed as a treatment method in combination with chemotherapy (14 patients - 12.7\%), neurosurgery (12 patients - 10.9\% or stereotactic radiosurgery ( 8 patients - $7.3 \%$ ). Results. The median overall survival (OS) from diagnosis MBM was 4.8 months ( $95 \% \mathrm{Cl} 4.1-5.2$ months). The analyses showed that the Karnofsky Performance Status and number of the MBM are independent significant prognostic factors. The analyses of OS, as a function of prognostic scores, showed that in the class with the best prognosis median OS was similar (7.2-10.7 months); and in the class with the worse prognosis median OS was also similar (range, 2.6-4.3 months). Conclusions. Our observations and data from literature showed that the presented scores can: distinguish classes of patients by prognosis before treatment, guide the choice of treatment methods and help design strategies for patient selection in clinical trials but they did not fully discriminate between unfavourable groups.
\end{abstract}

NOWOTWORY J Oncol 2016; 66, 5: 367-374

Key words: melanoma, brain metastases, prognostic index

\section{Introduction}

Melanoma gives rise to $7-13 \%$ of all brain metastases (MBM - melanoma brain metastases) and is ranked as third leading cause of brain metastases, after lung cancer (30-60\%) and breast cancer (15-25\%) [1-8]. The prevalence of melanoma brain metastases in patients with locoregional advancement melanoma is about $10 \%$, whereas in patients with a generalised stage of the disease, it exceeds $15-46 \%[1,2,4,6,8]$. In almost half of the patients with melanoma, MBM is the cause of death, whilst autopsies shows the presence of MBM in $50-75 \%$ of such melanoma cases $[1,2,4,5,8-11]$.

The prognosis of patients with MBM is poor with a mean survival of 3-6 months; in patients treated solely with cor- ticosteroids, the mean survival is 2 months, whilst after the whole brain radiotherapy (WBRT) - it is about 3-4 months $[6,8,10,12-16]$. Numerous publication data suggests that some patients may benefit from surgical treatment or radio-surgery (with the application of stereotactic methods of radiotherapy - SBRT), where the survival period varies between a few months and more than one year (12 months). This, however, concerns mostly patients with isolated metastatic foci (1-3 metastases, with a diameter up to $3.5 \mathrm{~cm}$ ) [17-22].

Patients with MBM also receive systemic treatment, yet this kind of treatment has limited effectiveness. There are also attempts to undertake chemotherapy (temozolomide, fotemustine, thalidomide) and immunotherapy. The latter

Department of Oncology

Maria Sklodowska-Curie Memorial Cancer Center and Institute of Oncology

Kraków Branch, Kraków, Poland 
method comprises the use of anti-CTLA-4 antibodies against cytotoxic antigen- 4 of $\mathrm{T}$ lymphocytes (iplimumab) or BRAF receptor serine/threonine protein kinase inhibitors (wemurafenib, dabrafenib). However, the effectiveness of systemic treatment is here limited; this concerns both chemotherapy and immunotherapy and cases of MBM in patients without any symptoms or whose symptoms are very limited $[2,4$, 12, 23-29].

A solid and repetitive prognostic model may be helpful in the selection of the treatment method and planning the strategy of patient selection for clinical studies in future. There have been many publications with prognostic indexes for patients with brain metastases of various types of cancers: RPA-RTOG (Recursive Partitioning Analysis - Radiation Therapy Oncology Group), Rotterdam, SIR (Score Index for Radiosurgery), BSBM (Basic Score for Brain Metastases), Rades et al. score, GPA (Graded Prognostic Assessment), MM-GKR (Malignant Melanoma — Gamma Knife Radiosurgery), MS-GPA (melanoma-specific GPA) [30-36].

In 1997 Gaspar published the RPA index; on the basis of the collective analysis of the results of 3 RTOG studies, he distinguished some prognostic groups of patients with brain metastases of various types of cancers. Class I comprised patients below 65 years of age, with performance states (according to the Karnofsky score - KPS) of at least 70\%, with controlled core disease and without extracranial metastases; class III comprised patients with a KPS below $70 \%$, whilst class II - all other remaining subjects [30].

In 2008 Sperduto proposed a new system, GPA, in which a specific score $(0,0.5$ and 1$)$ was attributed to 4 factors, being: the age ( $\geq 60 ; 50-59 ;<50)$, the number of brain metastases ( $>3 ; 2-3 ; 1)$, the KPS $(<70 ; 70-80 ; 90-100)$ and the number of extracranial metastases (none or present). The patients with the best prognoses received GPA 4, and those with the worst: 0-1 [35, 37, 38].

In 2010 Sperduto validated the previous text, taking into consideration the general condition of the patients and the number of metastatic foci, as significant prognostic factors in patients with MBM. The result was the introduction of DS-GPA (diagnosis-specific GPA), where 2 points were attributed for KPS 90-100 and a single MBM, 1 point for KPS 70-80 and 2-3 MBM; the patients with the best prognoses had DS-GPA 4 [14, 36-38].

The objective of the study was the retrospective evaluation of the usefulness and the limitations of the application, in a clinic, of 3 prognostic scales for patients with MBM.

\section{Materials and methods}

The analysis concerned 110 subjects ( 66 men and 44 women) with MBM, who were treated for melanoma in the Oncology Centre in Kraków from 1985-2012. These cases accounted for $15.5 \%$ all the (710) patients treated for melanoma during that period. The diagnosis of MBM was
Table I. Populational and clinical characteristics of the analysed group of 110 melanoma patients with brain metastases

\begin{tabular}{|c|c|c|}
\hline Property & $\begin{array}{c}\text { Number } \\
\text { of patients }\end{array}$ & $\%$ \\
\hline \multicolumn{3}{|l|}{ Age (years): } \\
\hline$<50$ & 18 & 16.4 \\
\hline $50-60$ & 68 & 61.8 \\
\hline $61-65$ & 14 & 12.7 \\
\hline$>65$ & 10 & 9.1 \\
\hline \multicolumn{3}{|l|}{ Sex: } \\
\hline Males & 66 & 60.0 \\
\hline Females & 44 & 40.0 \\
\hline \multicolumn{3}{|c|}{ Period free from metastases (months): } \\
\hline$<24$ & 54 & 49.1 \\
\hline$\geq 24$ & 56 & 50.9 \\
\hline \multicolumn{3}{|c|}{ Neurological symptoms: } \\
\hline Present & 98 & 89.1 \\
\hline Absent & 12 & 10.9 \\
\hline \multicolumn{3}{|c|}{ Number of brain metastases: } \\
\hline 1 & 40 & 36.4 \\
\hline $2-3$ & 22 & 20.0 \\
\hline$>3$ & 48 & 43.6 \\
\hline \multicolumn{3}{|c|}{ Control of the primary focus: } \\
\hline Yes & 65 & 59.1 \\
\hline No & 45 & 40.9 \\
\hline \multicolumn{3}{|c|}{ Extracranial metastases: } \\
\hline Present & 90 & 81.8 \\
\hline Absent & 20 & 18.2 \\
\hline \multicolumn{3}{|l|}{ KPS: } \\
\hline $90-100$ & 12 & 10.9 \\
\hline $70-80$ & 60 & 54.6 \\
\hline$<70$ & 38 & 34.5 \\
\hline \multicolumn{3}{|c|}{$\mathrm{LDH}^{*}$ in blood serum: } \\
\hline$\leq 240 \mathrm{UI} / \mathrm{mL}$ & 46 & 41.8 \\
\hline$>240 \mathrm{UI} / \mathrm{mL}$ & 64 & 58.2 \\
\hline Total & 110 & 100.0 \\
\hline
\end{tabular}

*LDH - lactate dehydrogenase

made on the basis of imaging diagnostics: computer tomography $(\mathrm{CT})$ and/or magnetic resonance imaging (MRI). The source of information concerning the pathomorphological characteristics of the tumour, clinical data, the course of the disease, survival and causes of death was medical documentation (patient information charts, hospital files, the files of GPs as well as the state cancer registers (in cases when it was necessary). Table I presents the clinical characteristics of the pathomorphological characteristics of the patients'tumours.

The mean age of the subjects was 55 years (range: from 34 to 72). The average time for the confirmation of the 
development of the brain metastases, calculated from the diagnosis of the melanoma was 31 months (range: from 0.2 to 145 months). In 89 patients (89.1\%), neurological symptoms were present (headaches, nausea, epilepsy and focal defects), whist in the remaining 12 patients (10.9\%) clinically asymptomatic brain metastases were found. The number of metastatic foci in the brain was the following: 1 in 40 (36. 4\%) subjects, 2-3 in 2 (20\%) subjects and more than 3 in 48 (43.6\%) subjects. In 65 (59.1\%) the primary disease was controlled; in 20 (18.2\%) subjects MBM were the only location of the metastases, whilst in 90 (81.8\%) subjects, the brain metastases co-existed with metastases in other locations: lungs (72-65.5\%), liver (43-39.1\%), skin or subcutaneous tissue (35-31.8\%), bones (16-14.5\%) and other locations (spleen, adrenal glands, peritoneum, extraperitoneal space) - 42 (38.2\%). The general performance score KPS $\geq 70$ was diagnosed in $72(65.5 \%)$ subjects, whereas $<70$ in 38 (34.5\%) subjects. The cut-off values of the lactate dehydrogenase (LDH) activity in blood serum were adopted to be $240 \mathrm{UI} / \mathrm{mL}$ and in 64 (58.2\%) subjects an elevated level of this enzyme was found [16].

\section{Treatment}

All patients were treated with external beam radiotherapy $\left({ }^{60} \mathrm{Co}\right.$ source or $6 \mathrm{MV}$ photon beams). The irradiated area comprised the whole brain (WBRT), where the administered doses was 40Gy in 20 fractions with the use of the opposite fields technique. Out of 110 subjects, in $76(69.1 \%)$ of them, solely WBRT was applied and in $14(12.7 \%)$ subjects WBRT was combined with temozolomide $\left(200 \mathrm{mg} / \mathrm{m}^{2}, 5\right.$ days in cycles every 28 days), whilst in 12 (10.9\%) cases, WBRT was used as an adjuvant treatment after a neurosurgical intervention; in 8 (7.3\%) subjects WBRT was applied after radiosurgery (SRS). It must be pointed out that the patients with isolated metastatic foci were treated with neurosurgery and, if the tumour was non-resectable - they were treated by radiosurgery with the dose of 15-25 Gy in 1 fraction.

\section{Statistical analysis}

The evaluation criterion was adopted to be the survival period calculated from the MBM diagnosis till the death date, or, in the case of survival patients, till the last follow-up visit. The survival curves and the average survival with 95\% relative confidence intervals $(95 \% \mathrm{Cl})$ were evaluated with the Kaplan Meier method and then compared with the log-rank test. There were single and multivariance analyses carried out with the Cox method. In all the statistical analyses, the significance level was adopted for $p \leq 0.05$.

\section{Results}

\section{Survivals and prognostic factors}

In the analysed group, the mean survival period calculated from the MBM diagnosis was 4.8 months $(95 \% \mathrm{Cl}$;

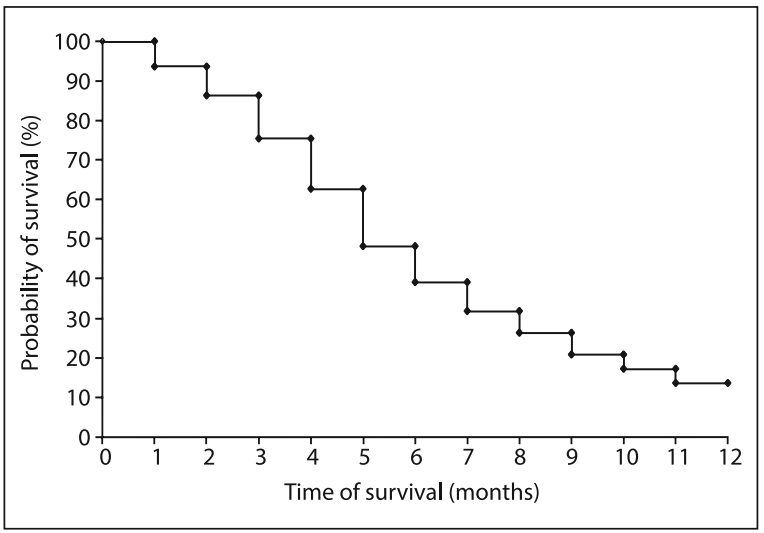

Figure 1. Survival curve of 110 melanoma patients with brain metastases

4.1-5.2 months). Depending on the applied methods of the MBM treatment, this value was: 9.2 months (surgery and WBRT); 7.4 months (SRT and WBRT); 4 months (solely WBRT) and 3.8 months (WBRT + temozolomide). In all subjects, the 6- and 12 month survival periods were $39.1 \%$ and $13.6 \%$ respectively. Figure 1 presents the survival curve for a group of 110 subjects with MBM.

The results of one-way analysis of variance showed that favourable prognostic factors were: KPS $\geq 70$, the presence of a single MBM focus and the lack of metastases in other (extracranial) locations (Tab. II). However, in relation to sex, age, the period of development of brain metastases, the presence of neurological symptoms, the control of the primary disease and the LDH blood serum level, no prognostics value was found.

Table III presents the final model of the Cox multivariate analysis. It was found that independent prognostic factors for patients with MBM were the general performance (KPS)

Table II. Statistically significant prognostic factors in reference to survival

\begin{tabular}{lcc}
\hline Factor & $\begin{array}{c}\text { Mean survival period } \\
\text { (months) }\end{array}$ & $\mathbf{p}$ \\
& (95\% confidence interval) & \\
\hline KPS: & $7.6(6.1-17.0)$ & $<0.001$ \\
$90-100$ & $5.4(4.2-6.7)$ & \\
$70-80$ & $3.8(0.4-4.1)$ & \\
$<70$ & & \\
The number of MBM foci: & $7.6(5.8-17.0)$ & \\
1 & $4.9(3.7-5.9)$ & \\
$2-3$ & $3.4(0.4-3.9)$ & \\
$>3$ & & \\
Extracranial metastases: & $6.2(4.7-17.0)$ & \\
Present & $4.2(0.4-5.2)$ & \\
Absent &
\end{tabular}

KPS - Karnofsky Performance Status; MBM — melanoma brain metastases 
Table III. The results of Cox multivariance analysis

\begin{tabular}{lccc}
\hline Variant & $\begin{array}{c}\text { Relative } \\
\text { risk }\end{array}$ & $\begin{array}{c}95 \% \\
\text { confidence } \\
\text { interval }\end{array}$ & p \\
\hline KPS: & 1.00 & & $<0.001$ \\
$90-100$ & 1.47 & $0.7-2.6$ & \\
$70-80$ & 3.15 & $1.7-6.1$ & \\
$<70$ & & & \\
MBM number: & 1.00 & & \\
1 & 1.52 & $0.92-2.43$ & \\
$2-3$ & 1.98 & $1.41-3.3$ & \\
$>3$ & & & 0.176 \\
Extracranial metastases: & 1.00 & & \\
Present & 1.18 & $0.7-1.56$ & \\
Absent & & & \\
\hline KPS - Karnofsky performance status; MBM - melanoma brain metastases & & \\
& & & \\
\hline
\end{tabular}

and the number of the MBM. Figures 2 and 3 present the probability of survival as a function of these two prognostic factors.

\section{Analysis of the usefulness of the clinical application of prognostic scales: RPA-RTOG, GPA and MS-GPA in patients with MBM}

Assigning patients to specific groups of the evaluated prognostic scales was as follows:

- According to RPA-RTOG - 20 (18.2\%) patients met the criteria of class I, whilst 90 (81.8\%) subjects met the criteria of classes II and III;

- According to GPA - 18 (16.4\%) patients met the criteria of class I and II, and 92 (83.6\%) subjects met the criteria of classes III and IV;

- According to MS-GPA - 40 (36.4\%) patients met the criteria of classes I-II, and 70 (63.6\%) subjects met the criteria of classes III-IV.

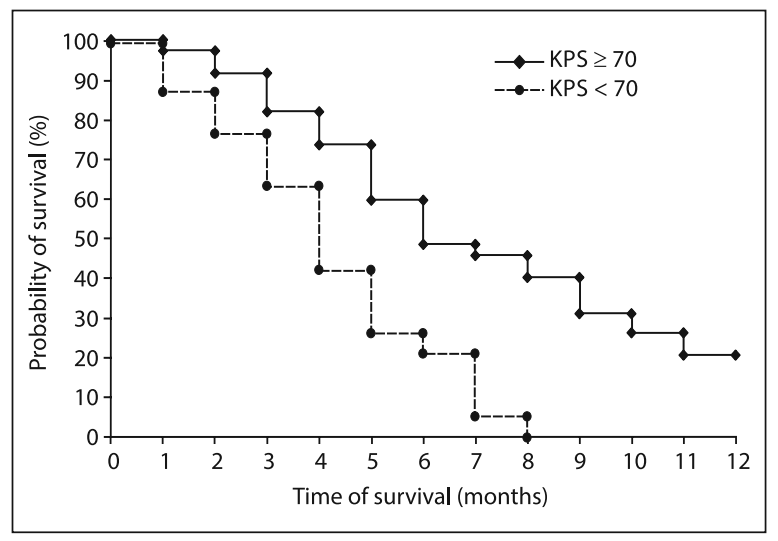

Figure 2. Survival curve of 110 melanoma patients with brain metastases, related to their general status

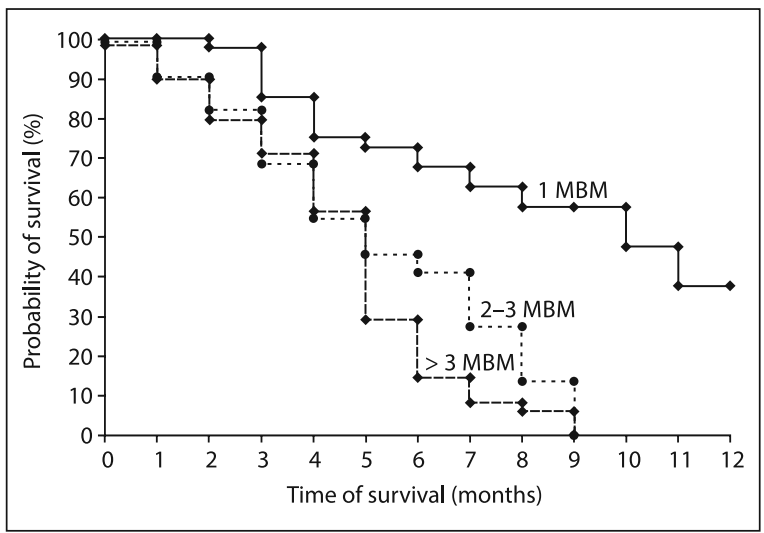

Figure 3. Survival curve of 110 melanoma patients with brain metastases, related to the number of metastatic foci

Table IV lists the survival results of the patients with MBM depending on the prognostic scale index.

It was found that in the classes which were characterised with the best prognoses (i.e. RPA-RTOG — I group, GPA I and II group and MS-GPA — I and II group) the mean values of the survival period were comparable and amounted to between 7.2 and 10.7 months. In the classes with the worst prognoses (i.e. RPA-RTOG group II and III, GPA — III and IV as well as MS-GPA - III and IV), the mean survival periods were also comparable, yet shorter (from 2.6 to 4.3 months) than in patients assigned to the groups with better prognoses.

Table IV. Mean survival period depending on the patient's assigning to specific classes of the evaluated prognostic indices (RPA-RTOG, GPA and SM-GPA)

\begin{tabular}{|c|c|c|c|}
\hline $\begin{array}{l}\text { Prognostic } \\
\text { indices }\end{array}$ & $\begin{array}{c}\text { Number of } \\
\text { subjects (\%) }\end{array}$ & $\begin{array}{l}\text { Average survival } \\
\text { period (months) } \\
\text { (95\% confidence } \\
\text { interval) }\end{array}$ & $p$ \\
\hline $\begin{array}{l}\text { The entire } \\
\text { group }\end{array}$ & $110(100.0)$ & $4.8(0.4-17.0)$ & \\
\hline \multicolumn{4}{|l|}{ RPA-RTOG : } \\
\hline I & $20(18.2)$ & $9.6(6.0-17.0)$ & $<0.002$ \\
\hline II & $52(47.3)$ & $4.5(1.9-8.4)$ & \\
\hline III & $38(34.5)$ & $2.6(0.4-3.8)$ & \\
\hline \multicolumn{4}{|l|}{ GPA: } \\
\hline I & $8(7.3)$ & $10,7(5.8-17.0)$ & $<0.002$ \\
\hline$\|$ & $10(9.1)$ & $7.2(6.0-8.1)$ & \\
\hline III & $22(20.0)$ & $3.8(1.8-5.7)$ & \\
\hline IV & $70(63.6)$ & $2.7(0.4-3.9)$ & \\
\hline \multicolumn{4}{|l|}{ MS-GPA: } \\
\hline I & $12(10.9)$ & $10.4(6.8-17.0)$ & $<0.001$ \\
\hline II & $28(25.5)$ & $8.2(6.0-1.0)$ & \\
\hline III & $22(20.0)$ & $4.3(1.0-5.4)$ & \\
\hline IV & $48(43.6)$ & $3.1(0.4-4.1)$ & \\
\hline
\end{tabular}


Table V. Treatment results in patients with melanoma metastases in brain in published data

\begin{tabular}{|c|c|c|}
\hline Author [number in bibliography list], year of publication & Mean survival period (months) & Remarks \\
\hline \multirow[t]{4}{*}{ Konstadoulakis et al. [28], 2000} & 3.9 & 12-month survival: \\
\hline & & surgery + SRS and/or WBRT - $28.3 \%$ \\
\hline & & radiotherapy $-6.7 \%$ \\
\hline & & not treated subjects $-3.5 \%$ \\
\hline Buchsbaum et al. [13], 2002 & 5.5 & - \\
\hline Harrison et al. [6], 2003 & 4.0 & - \\
\hline Fife et al. [42], 2004 & 4.1 & - \\
\hline \multirow[t]{4}{*}{ Meier et al. [43], 2004} & 4.8 & Survival: \\
\hline & & 6 months $-36 \%$ \\
\hline & & 12 months $-14 \%$ \\
\hline & & 24 months $-5 \%$ \\
\hline Raizer et al. [44], 2008 & 5.2 & - \\
\hline Staudt et al. [40], 2010 & 5.0 & - \\
\hline Eigentler et al. [5], 2011 & 5.0 & - \\
\hline Davies et al. [1], 2011 & 4.7 & - \\
\hline Zakrzewski et al. [41], 2011 & 5.8 & - \\
\hline Partl et al. [16], 2013 & 2.3 & Only WBRT \\
\hline \multirow[t]{2}{*}{ Zakauskaite et al. [45], 2013} & 4.5 & MBM without neurological symptoms \\
\hline & & 12-month survival $-12.5 \%$ \\
\hline \multirow[t]{3}{*}{ Presented study, 2016} & 4.8 & Survival: \\
\hline & & 6 months $-35.1 \%$ \\
\hline & & 12 months $-13.6 \%$ \\
\hline
\end{tabular}

MBM — melanoma brain metastases; SRS — stereostatic radiosurgery; WBRT — whole brain radiotherapy

\section{Discussion}

The objective of this analysis was to evaluate the usefulness of the application, in a clinic, of 3 prognostic scales (RPA-RTOG, GPA and MS-GPA) in reference to patients with MBM, in whom various therapeutic methods were used. The methods of treatment used in the analysed group of patients were similar to those discussed in the publications and concerned retrospective studies [3, 5-8, 13, 16, 37, 39-45]. Table V presents the site's results and those presented by other authors.

The results of the multivariance analysis pointed out that the KPS and MBM number were independent prognostic factors in the patients with MBM. The published data definitively indicate the prognostic value of KPS; in the majority of publications, the statistically significant adverse prognostic factor is a KPS below 70 [5-8, 14, 16, 17, 30, 32-36], whilst in other publications, this concerns a KPS below 80 [7, 32, 33].

Table VI presents the values of average survival periods of patients with MBM depending on the KPS score, which were 5.9-6.3 months for KPS $\geq 70$ and were definitely lower in patients with a poorer general performance (KPS $<70$ ), where they varied from 1.8 to 3.8 months. The results based on the site's material are comparable with those presented with other authors $[5,13,14,37,40,46]$.
Table VI. Mean survival in correlation with Karnofsky performance status (KPS)

\begin{tabular}{|c|c|c|}
\hline $\begin{array}{l}\text { Author [number in bibliography list], } \\
\text { year of publication }\end{array}$ & KPS & $\begin{array}{l}\text { Mean OS } \\
\text { (months) }\end{array}$ \\
\hline \multirow[t]{2}{*}{ Buchsbaum et al. [13], 2002} & $\geq 70$ & 6.3 \\
\hline & $<70$ & 1.8 \\
\hline \multirow[t]{2}{*}{ Gaudy-Marqueste et al. [7], 2006} & $>80$ & 5.98 \\
\hline & $\leq 80$ & 2.25 \\
\hline \multirow[t]{2}{*}{ Mathieu et al. [46], 2007} & $90-100$ & 6.3 \\
\hline & $<90$ & 2.9 \\
\hline \multirow[t]{2}{*}{ Staudt et al. [40], 2010} & $>80$ & 6.0 \\
\hline & $\leq 80$ & 3.0 \\
\hline \multirow[t]{2}{*}{ Eigentler et al. [5], 2011} & $\geq 70$ & 6.0 \\
\hline & $<70$ & 3.0 \\
\hline \multirow[t]{3}{*}{ Nieder et al. [37], 2011} & $90-100$ & 15.1 \\
\hline & $70-80$ & 4.6 \\
\hline & $<70$ & 2.0 \\
\hline \multirow[t]{3}{*}{ Marcus et al. [14], 2014} & $90-100$ & 10.4 \\
\hline & $70-80$ & 6.1 \\
\hline & $<70$ & 4.5 \\
\hline \multirow[t]{2}{*}{ Presented study 2016} & $\geq 70$ & 6.2 \\
\hline & $<70$ & 3.9 \\
\hline
\end{tabular}


Table VII. Mean survival in correlation with the MBM number

\begin{tabular}{|c|c|c|}
\hline $\begin{array}{l}\text { Author [number in bibliography } \\
\text { list], year of publication }\end{array}$ & $\begin{array}{c}\text { MBM } \\
\text { number }\end{array}$ & $\begin{array}{c}\text { Mean survival } \\
\text { (months) }\end{array}$ \\
\hline \multirow[t]{2}{*}{ Buchsbaum et al. [13], 2002} & 1 & 7.9 \\
\hline & $>1$ & 4.6 \\
\hline \multirow[t]{2}{*}{ Gaudy-Marqueste et al. [7], 2006} & 1 & 5.49 \\
\hline & $>1$ & 4.56 \\
\hline \multirow[t]{5}{*}{ Mathieu et al. [46], 2007} & 1 & 6.8 \\
\hline & $>1$ & 3.6 \\
\hline & $2-3$ & 4.5 \\
\hline & $4-6$ & 3.2 \\
\hline & $>6$ & 2.4 \\
\hline \multirow[t]{3}{*}{ Staudt et al. [40], 2010} & 1 & 8.0 \\
\hline & 2 & 5.0 \\
\hline & $>2$ & 3.0 \\
\hline \multirow[t]{2}{*}{ Eigentler et al. [5], 2011} & 1 & 7.0 \\
\hline & $>1$ & 4.0 \\
\hline \multirow[t]{2}{*}{ Davies et al. [1], 2011} & $1-3$ & 5.92 \\
\hline & $>3$ & 3.52 \\
\hline \multirow[t]{3}{*}{ Nieder et al. [37], 2011} & 1 & 5.9 \\
\hline & $2-3$ & 3.7 \\
\hline & $>3$ & 3.1 \\
\hline \multirow[t]{3}{*}{ Marcus et al. [14], 2014} & 1 & 7.8 \\
\hline & $2-3$ & 6.0 \\
\hline & $>3$ & 3.8 \\
\hline \multirow[t]{3}{*}{ Presented study, 2016} & 1 & 7.6 \\
\hline & $2-3$ & 4.9 \\
\hline & $>3$ & 3.4 \\
\hline
\end{tabular}

The other, generally accepted prognostic factor is the number of MBM foci. The best prognoses concerned the patients with a single metastatic focus $[17,32,35,36,40]$; the increase of the MBM number is associated with a deterioration of the patient's prognosis [17, 32, 35, 36].

Staudt et al. claim that relatively good prognoses can only be made in patients with a single metastatic focus [40]. Rades et al. in turn, distinguishes two groups of patients: with 1-3 MBM foci and with more than $3 \mathrm{MBM}$ foci; and Weltman and Sperduto propose breaking down the patient groups into 3 categories: with 1, with $2-3$ and more than 3 MBM [32, 34, 36].

Table VII presents the mean survival periods of patients with MBM depending on the number of metastatic foci in the brain, and thus in the case of isolated metastases the survival periods were $5.9-8$ months and were twice as short in the case of multiple MBMs. In this case also the site's experience was compared with the results published by other authors $[1,5,13,14,37,40,46]$.

Some investigators point to the adverse prognostics significance of the presence of metastases outside the brain, in particular in the lungs, liver, spleen and adrenal glands, and, to a lesser degree, in the bones, lymph nodes and skin [5, 6, 8, 30, 31, 33-35, 40-42]. In the site's own material, in a single-variance analysis, it was shown that the co-existence of the metastases in extracranial locations was an adverse prognostic factor, which was, however, not confirmed by the results of the multivariance analysis. According to the published data, the factors which play a prognostic role are also the age, blood serum LDH level before treatment, the time of MBM onset and the presence of neurological symptom as well as the control degree of the primary disease $[5,7,8,14$, $30,32-35,40-42,45]$.

Table VIII. Mean survival in correlation with the class in RPA-RTOG scale

\begin{tabular}{lcc}
\hline $\begin{array}{l}\text { Author [number in } \\
\text { bibliography list], year } \\
\text { of publication }\end{array}$ & $\begin{array}{c}\text { Prognostic } \\
\text { class }\end{array}$ & $\begin{array}{c}\text { Mean survival } \\
\text { (months) }\end{array}$ \\
\hline Buchsbaum et al. [13], 2002 & I & 10.5 \\
& III & 5.9 \\
Harrison et al. [6], 2003 & I & 6.5 \\
& II & 3.5 \\
Morris et al. [8], 2004 & III & 2.5 \\
& I & 5.0 \\
Staudt et al. [40], 2010 & II & 2.4 \\
& III & $<1$ \\
Eigentler et al. [5], 2011 & I & 9.0 \\
& II & 5.0 \\
Presented study, 2016 & III & 2.0 \\
& I & 7.0 \\
& II & 5.0 \\
& III & 3.0 \\
& I & 9.6 \\
& II & 4.5 \\
& III & 2.6 \\
\hline
\end{tabular}

Table VIII, IX and X present the survival periods of patients with MBM depending on their assignment to specific classes within the prognostic scales RPA-RTOG, GPA and MS-GPA.

In the case of the RPA-RTOG scale, it was found that the mean survival period of the patients assigned to class I was 5-10.5 months, whilst in class II: 2.4-5.9 months and in class III $<1-3$ months; the presented results, based on the site's data, are similar to those published by other authors.

The above-discussed author's own observations and the published data point both to the benefits and limitations related to the use of prognostic indices in patients with MBM $[13,35,37,42,47]$ 
Table IX. Mean survival in correlation with the class in GPA prognostic scale.

\begin{tabular}{lcccccc}
\hline Author [number in bibliography list], year of publication & \multicolumn{4}{c}{ Median survival (months) } \\
\cline { 2 - 6 } & \multicolumn{3}{c}{ Prognostic class (number of patients) } & Total \\
\hline Nieder et al. [37], 2011 & I & II & III & IV & \\
Presented study, 2016 & 12.8 & 7.8 & 6.3 & 2.3 & 3.7 \\
\hline
\end{tabular}

Table X. Median survival in correlation with prognostic class in MS-GPA scale

\begin{tabular}{lcccc}
\hline Author [number in bibliography list], year of publication & \multicolumn{3}{c}{ Median survival (months) } \\
\cline { 2 - 4 } & \multicolumn{2}{c}{ Prognostic class (number of patients) } & III & II \\
\hline Sperduto et al. [36], 2010 & 13.2 & 8.8 & 4.7 & 3.4 \\
Nieder et al. [37], 2011 & 12.7 & 7.5 & 3.7 & 3.1 \\
Presented study, 2016 & 10.4 & 8.2 & 4.3 & 3.1 \\
\hline
\end{tabular}

1. The benefits connected with the use of the prognostic indices (RPA-RTOG, GPA, MS-GPA):

- Allow for the patients' classification with regards to their prognoses;

- Facilitate the choice of the treatment method: from more aggressive for patients with a chance of a prolongation of the survival period and alleviation of symptoms to less aggressive for patients with the advanced disease; all the 3 indices (in particular GPA and MS-GPA) allow for the identification of patients with favourable prognosis, which might be useful for the qualification of patients for surgical treatment or SRS;

- Assist in the determination of the classification criteria for clinical trials;

- Facilitate the comparison of the homogeneity of the patient groups for retrospective analysis.

2. The limitation of the prognostic indices:

- The discussed indices (RPA-RTOG, GPA, MS-GPA) do not fully distinguish between the groups with adverse prognosis (RPA-RTOG class II vs class III, GPA and MS-GPA class III (BSC);

- RPA-RTOG does not take into consideration the number of MBM foci; the RTOG 9508 study showed that the number of MBM foci is a significant prognostic factor; the results of the author's multivariance analysis showed that the KPS and MBM foci number were independent prognostic factors. Moreover, the RPA-RTOG index requires control over the metastatic foci located outside the brain, which is difficult in evaluation and/or burdened with significant subjectivity;

- MS-GPA takes into consideration solely the KPS and MBM foci number, whereas a few large studies showed that the presence of extracranial metastases is a signifi- cant prognostic factor, which is also confirmed by the author's own research $[8,47]$.

\section{Conclusions}

The introduction of prognostic indices to everyday clinical practice as well as their continual improvement are indicative of a progress in the treatment of MBM patients. Yet, these indices should be used with appropriate caution and critical evaluation.

\section{Conflicts of interest: none declared}

\section{Bogumiła Szyszka-Charewicz MD, PhD \\ Department of Oncology \\ Maria Sklodowska-Curie Memorial Cancer Center \\ and Institute of Oncology \\ Kraków Branch \\ Garncarska 11, 31-115 Kraków, Poland \\ e-mail:z5szyszk@cyfronet.pl}

\section{Received \& Accepted: 13 Jun 2016}

\section{References}

1. Davies MA, Liu P, Mclntyre $S$ et al. Prognostic factors for survival in melanoma patients with brain metastases. Cancer 2011; 117: 1687-1696.

2. Carlino MS, Fogarty GB, Long GV. Treatment of melanoma brain metastases: a new paradigm. Cancer J 2012; 18: 208-212.

3. Majer M, SamlowskiWE. Management of metastatic melanoma patients with brain metastases. Curr Oncol Rep 2007; 9: 411-416.

4. Durando X, Mansard S, Daste A et al. Stratégies thérapeutiques et traitements systémiques des métastases cérébrales du melanoma. Bull Cancer 2013; 100: 23-28.

5. Eigentler TK, Figl A, Krex D et al. Number of metastases, serum lactate dehydrogenase level, and type of treatment are prognostic factors in patients with brain metastases of malignant melanoma. Cancer 2011; 117: $1697-1703$

6. Harrison BE, Johnson JL, Clough RW et al. Selection of patients with melanoma brain metastases for aggressive treatment. Am J Clin Oncol 2003; 26: 354-357. 
7. Gaudy-Marqueste C, Regis JM, Muracciole X et al. Gamma-Knife radiosurgery in the management of melanoma patients with brain metastases: a series of 106 patients without whole-brain radiotherapy. Int J Radiat Oncol Biol Phys 2006; 65: 809-816.

8. Morris $\mathrm{SL}$, Low $\mathrm{SH}, \mathrm{A}^{\prime}$ Hern RP et al. A prognostic index that predicts outcome following palliative whole brain radiotherapy for patients with metastatic malignant melanoma. Br J Cancer 2004; 91: 829-833.

9. Samlowski WE, Watson GA, Wang $\mathrm{M}$ et al. Multimodality treatment of melanoma brain metastases incorporating stereotactic radiosurgery (SRS). Cancer 2007; 109: 1855-1862.

10. Bafaloukos $\mathrm{D}, \mathrm{Gogas} \mathrm{H}$. The treatment of brain metastases in melanoma patients. Cancer Treat Rev 2004; 30: 515-520.

11. Powell S, Dudek AZ. Single-institution outcome of high-dose interleukin-2 (HD IL-2) therapy for metastatic melanoma and analysis of favorable response in brain metastases. Anticancer Res 2009; 29: 4189-4193.

12. Le Rhun É, Mateus $C$, Mortier L et al. Traitement systémique des métastases cérébrales de melanoma. Cancer Radiother 2015; 19: 48-54.

13. Buchsbaum JC, Suh JH, Lee SY et al. Survival by radiation therapy oncology group recursive partitioning analysis class and treatment modality in patients with brain metastases from malignant melanoma: a retrospective study. Cancer 2002; 94: 2265-2272.

14. Marcus DM, Lowe M, Khan MK et al. Prognostic factors for overall survival after radiosurgery for brain metastases from melanoma. $\mathrm{Am} \mathrm{J}$ Clin Oncol 2014; 37: 580-584.

15. Hauswald $\mathrm{H}$, Dittmar JO, Habermehl $\mathrm{D}$ et al. Efficacy and toxicity of whole brain radiotherapy in patients with multiple cerebral metastases from malignant melanoma. Radiat Oncol 2012; 7: 130.

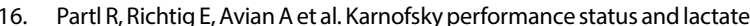
dehydrogenase predict the benefit of palliative whole-brain irradiation in patients with advanced intra- and extracranial metastases from malignant melanoma. Int J Radiat Oncol Biol Phys 2013; 85: 662-666.

17. Mathieu D, Kondziolka D, Cooper PB et al. Gamma knife radiosurgery in the management of malignant melanoma brain metastases. Neurosurgery 2007; 60: 471-481.

18. Grob JJ, Regis J, Laurans R et al. Radiosurgery without whole brain radiotherapy in melanoma brain metastases. Club de Cancerologie Cutanee. Eur J Cancer 1998; 34, 1187-1192.

19. Manon R, O'Neill A, Knisely J et al. Phase II trial of radiosurgery for one to three newly diagnosed brain metastases from renal cell carcinoma, melanoma and sarcoma: an Eastern Cooperative Oncology Group Study [E6397]. J Clin Oncol 2005; 23: 8870-8876.

20. Radbill AE, Fiveash JF, Falkenberg ET et al. Initial treatment of melanoma brain metastases using gamma knife radiosurgery: an evaluation of efficacy and toxicity. Cancer 2004; 101: 825-833.

21. Rate WR, Solin LJ, Turrisi AT. Palliative radiotherapy for metastatic malignant melanoma: brain metastases, bone metastases, and spinal cord compression. Int J Radiat Oncol Biol Phys 1988; 15: 859-864.

22. Wronski M, Arbit E. Surgical treatment of brain metastases from melanoma: a retrospective study of 91 patients. J Neurosurg 2000; 93: 9-18.

23. Margolin K, Ernstoff MS, Hamid O et al. Ipilimumab in patients with melanoma and brain metastases: an open-label, phase 2 trial. Lancet Oncol 2012; 13: 459-465.

24. Long GV, Trefzer U, Davies MA et al. Dabrafenib in patients with Val600Glu or Val600Lys BRAF-mutant melanoma metastatic to the brain (BREAK-MB): a multicentre, open-label, phase 2 trial. Lancet Oncol 2012; 13: 1087-1095.

25. Dummer R, Goldinger SM, Turtschi CP et al. Vemurafenib in patients with BRAF(V600) mutation-positive melanoma with symptomatic brain metastases: final results of an open-label pilot study. Eur J Cancer 2014; 50: 611-621.

26. Mathew M, Tam M, Ott PA et al. Ipilimumab in melanoma with limited brain metastases treated with stereotactic radiosurgery. Melanoma Res 2013; 23: 191-195.
27. Dzienis MR, Atkinson VG: Response rate to vemurafenib in patients with B-RAF-positive melanoma brain metastases: a retrospective review. Melanoma Res 2014; 24: 349-353.

28. Konstadoulakis MM, Messaris E, Zografos $G$ et al. Prognostic factors in malignant melanoma patients with solitary or multiple brain metastases. Is there a role for surgery? J Neurosurg Sci 2000; 44: 211-218.

29. Devito N, Yu M, Chen R et al. Retrospective study of patients with brain metastases from melanoma receiving concurrent whole-brain radiation and temozolomide. Anticancer Res 2011; 31: 4537-4543.

30. Gaspar L, Scott C, Rotman M et al. Recursive partitioning analysis (RPA) of prognostic factors in three Radiation Therapy Oncology Group (RTOG) brain metastases trials. Int J Radiat Oncol Biol Phys 1997; 37: 745-751.

31. Lagerwaard FJ, Levendag PC, Nowak PJ et al. Identification of prognostic factors in patients with brain metastases: a review of 1292 patients. Int J Radiat Oncol Biol Phys 1999; 43: 795-803.

32. Weltman E, Salvajoli JV, Brandt RA et al. Radiosurgery for brain metastases: a score index for predicting prognosis. Int J Radiat Oncol Biol Phys 2000; 46: 1155-1161.

33. Lorenzoni J, Devriendt $\mathrm{D}$, Massager $\mathrm{N}$ et al. Radiosurgery for treatment of brain metastases: estimation of patient eligibility using three stratification systems. Int J Radiat Oncol Biol Phys 2004; 60: 218-224.

34. Rades D, Dunst J, Schild SE. A new scoring system to predicting the survival of patients treated with whole-brain radiotherapy for brain metastases. Strahlenther Onkol 2008; 184: 251-255.

35. Sperduto PW, Berkey B, Gaspar LE et al. A new prognostic index and comparison to three other indices for patients with brain metastases: an analysis of 1,960 patients in the RTOG database. Int J Radiat Oncol Biol Phys 2008; 70: 510-514.

36. Sperduto PW, Chao ST, Sneed PK et al. Diagnosis-specific prognostic factors, indexes, and treatment outcomes for patients with newly diagnosed brain metastases: a multi-institutional analysis of 4,259 patients. Int J Radiat Oncol Biol Phys 2010; 77: 655-661.

37. Nieder C, Marienhagen $\mathrm{K}$, Geinitz H et al. Can current prognostic scores reliably guide treatment decisions in patients with brain metastases from malignant melanoma? J Cancer Res Ther 2011; 7: 47-51.

38. Nieder C, Mehta MP. Prognostic indices for brain metastases - usefulness and challenges. Radiat Oncol 2009; 4:10.

39. Sperduto PW, Kased N, Roberge D et al. Summary report on the graded prognostic assessment: an accurate and facile diagnosis-specific tool to estimate survival for patients with brain metastases. J Clin Oncol 2012; 30: 419-425.

40. Staudt M, Lasithiotakis K, Leiter $U$ et al. Determinants of survival in patients with brain metastases from cutaneous melanoma. Br JCancer 2010; 102: 1213-1218.

41. Zakrzewski J, Geraghty LN, Rose AE et al. Clinical variables and primary tumor characteristics predictive of the development of melanoma brain metastases and post-brain metastases survival. Cancer 2011; 117: 1711-1720.

42. Fife KM, Colman MH, Stevens GN et al. Determinants of outcome in melanoma patients with cerebral metastases. J Clin Oncol 2004; 22: 1293-1300.

43. Meier S, Baumert BG, Maier T et al. Survival and prognostic factors in patients with brain metastases from malignant melanoma. Onkologie 2004; 27: 145-149.

44. Raizer JJ, Hwu WJ, Panageas KS et al. Brain and leptomeningeal metastases from cutaneous melanoma: survival outcomes based on clinical features. Neuro Oncol 2008; 10: 199-207.

45. Zukauskaite R, Schmidt H, Asmussen JT et al. Asymptomatic brain metastases in patients with cutaneous metastatic malignant melanoma. Melanoma Res 2013; 23: 21-26.

46. Mathieu D, Kondziolka D, Cooper PB et al. Gamma knife radiosurgery in the management of malignant melanoma brain metastases. Neurosurgery $2007 ; 60: 471-481$.

47. Le Scodan R, Massard C, Noël G. Facteurs pronostiques des métastases cérébrales. Bull Cancer 2013;100: 45-50. 